LaLonde, D., Leedy, M.G., \& Runk, K. (2003). Gender equity in mathematics: Beliefs of students, parents and teachers. School Science and Mathematics, 103(6), 285-292. Published by School Science and Mathematics Association (ISSN: 1949-8594).

\title{
Gender equity in mathematics: beliefs of students, parents, and teachers
}

Donna LaLonde, M. Gail Leedy, and Kristen Runk

\begin{abstract}
The attitudes about mathematics held by girls and boys participating in a regional mathematics contest, their parents, teachers, and mathematics coaches were investigated. Quantitative data regarding mathematics as a male domain, perception of importance of mathematics, confidence in learning mathematics, effectance motivation, and usefulness of mathematics were obtained. It was found that the traditional gender-based differences in the beliefs regarding mathematics persist even in these mathematically talented students. Furthermore, parents' responses to the questions regarding the role of mathematics revealed that mothers, more than fathers, focused on the computational aspects of mathematics, while fathers more than mothers mentioned the role of mathematics in science or as a language. Boys, fathers, and certain mathematics teachers admitted to a low level of gender stereotyping, as evidenced by their scores on the Mathematics as a Male Domain subscale. However, the girls, mothers, and mathematics coaches did not endorse this stereotyping. Unsolicited responses of girls and mothers, in fact, emphatically denied that gender stereotyping exists. These findings are discussed in terms of the need to resolve the essential conflicts between students', parents', and teachers' deeply held beliefs regarding the nature of mathematics, gender differences in mathematical abilities, and the desire for equity within mathematics education.
\end{abstract}


The role played by gender in mathematics education is multifaceted. Many reports of differences in mathematics performance related to gender have been presented over the past decades (Fennema, Carpenter, Jacobs, Franke, \& Levi, 1998; Maccoby \& Jacklin, 1974; Shibley-Hyde, Fennema, \& Lamon, 1990). Performance differences have been postulated to be due, at least in part, to attitudinal differences regarding mathematics. Fennema and Sherman (1977), using the Fennema-Sherman Mathematics Attitudes Scales, found several gender differences in high school students' attitudes. For the students in those high schools in which the males performed significantly better on mathematics achievement tests, Fennema and Sherman found that males also had higher scores on attitude scales, including Confidence in Learning Mathematics, viewing Mathematics as a Male Domain, Attitude Toward Success in Math, Mother's Support, Father's Support, and Usefulness of Mathematics. Since that initial report, similar gender differences in attitudes toward mathematics have been reported for different ages and using different measurement scales (Duffy, Gunther, \& Walters, 1997; Forgasz \& Leder, 1996; Kloosterman, 1988; Meyer \& Koehler, 1990; Stipek \& Gralinski, 1991; Tocci \& Engelhard, 1991). These attitudinal differences have also been reported for children who have been identified as academically gifted (Junge \& Dretzke, 1995; Siegle \& Reis, 1998; Terwilliger \& Titus, 1995).

Von Glaserfeld (1989), a leading constructivist philosopher, has suggested that the context in which humans find themselves is important in the acquisition of knowledge. The context for teaching and learning is, in large part, established by the interactions of students, teachers, and parents. Early studies focused on the role of parental attitudes in the development of attitudes their children hold toward mathematics. Parents of young boys expect their sons to develop mathematical skills earlier than the parents of young girls do (Blevins-Knabe \& Musun-Miller, 1991). Parents of older children believe that their daughters must work harder to achieve good grades in mathematics courses, and parents of boys place a higher emphasis on the importance of mathematics. It is significant that these parental attitudes were predictive of the students' achievement in mathematics courses (Parsons, Adler, \& Kaczala, 1982) and their belief in their mathematical abilities (Tiedemann, 2000). Gender-differentiated attitudes extend to parents of gifted children. Raymond and Benbow (1986) reported that mothers were more involved if their child was verbally talented, and fathers were more involved if the child was mathematically talented, reinforcing the idea that mathematics is a male domain.

Teachers' attitudes toward students' performance in mathematics classes parallel those of the parents. Again, girls are seen as successful due to their hard work (Jussim \& Eccles, 1992; Siegle \& Reis, 1998; Tiedemann, 2000), while boys' success is attributed to their talent (Jussim \& Eccles, 1992). As expected based on these differences in attitudes, there are also reports that teachers behave differently toward boys and girls in the classroom. Reports of preferential treatment of boys in the high school mathematics classroom have also been provided (American Association of University Women [AAUW], 1992; Becker, 1981).

Our research was designed to explore the attitudes toward and beliefs about the role of mathematics held by students. Specifically, we wished to investigate the beliefs of children who show an aptitude for and an interest in mathematics. Due to the proposed importance of the environmental context established by the interactions of students with teachers and parents, we 
also determined a need to investigate the attitudes of these students' parents, their mathematics coaches, and their mathematics teachers.

\section{METHOD}

\section{Participants}

Boys and girls, in the fourth, sixth and eighth grades who were participating in a regional mathematics contest were the primary participant group. The students attending this mathematics contest were selected by their schools based on their interest in the mathematics competition, and for the most part, their mathematical ability. Public and private schools representing urban and rural areas in northeastern Kansas were represented. The students' parents, both mothers and fathers, and the teachers also provided data. The teachers included those who "coach" the mathematics teams and those who teach mathematics but do not serve as coaches.

\section{Questionnaires and Data Collection}

Questionnaires for the students contained subscales from the Fennema-Sherman Mathematics Attitude Scale (Fennema \& Sherman, 1976). Mathematics as a Male Domain, Perception of Support for Mathematics to Father, Support for Mathematics to Mother, Confidence in Learning Mathematics, Usefulness of Mathematics, and Effectance Motivation were measured using a 12-item, 5-point, Likert-type format. For all subscales, higher values denote greater agreement with the scale.

Both the parents and the teachers received scales of Mathematics as a Male Domain and Usefulness of Mathematics. These scales were modified to represent the parent or teacher perspective, rather than the student perspective (e.g., "I study mathematics because I know how useful it is," was changed to, "People should study mathematics because of its usefulness.").

Packets containing consent forms, questionnaires and stamped return envelopes were given to all coaches of fourth-, sixth- and eighth-grade teams attending the mathematics competition. The coaches were asked to distribute these packets to the students and their parents. Packets for the mathematics teachers and the mathematics team coaches were also given to the coaches. The coaches were asked to distribute the teacher's packets to one mathematics teacher in their home school. 


\section{RESULTS}

\section{Students}

A total of 312 survey packets were given to the mathematics coaches to distribute to students. This number was purposefully high and based on the estimate of the maximum number of students who could participate from each school. The actual number of packets given to the students by the coaches is unknown, but was likely considerably lower, since many schools did not bring a full team of students to the contest. A total of 74 completed surveys were returned: 28 for fourth graders, 30 for sixth graders, and 16 for eighth graders. More boys than girls responded (41 and 33, respectively). The majority of the students lived with both parents (84.8\% of the girls and $87.8 \%$ of the boys). Five boys and five girls reported living with their mother, and no students reported living primarily with their father.

A mean score for each of the six subscales was determined for all students. Overall, the scores for the scales were quite high, with none of the mean scores falling below "4" on a 5-point scale, denoting high levels of Confidence, Effectance Motivation, Belief in the Importance of Math, and perception of Support from Mother and Support from Father. In contrast, the students had low levels of gender stereotyping of mathematics. Positive correlations among these six subscales were found, indicating a high degree of interrelatedness across subscales.

One-way analyses of variance (ANOVAs) were performed for each of the subscales, using gender as the main effect. Grade level was not used as an independent variable, due to the small number of participants represented in some of the resulting cells (e.g., $n=6$ for eighthgrade boys). Instead, the student's age was used as covariate. As shown in Figure 1, boys had higher agreement with the concept that Mathematics is a Male Domain than did the girls, $F(1,71)=4.34, p<.05$. Boys also had higher levels of Confidence in Mathematics Abilities (4.7 and 4.5 , respectively), $F(1,72)=4.53, p<.05$; and higher scores on the Mother scale $(4.7$ and 4.5 , respectively), $F(1,71)=4.18, p<.05$. Similar but nonsignificant differences were found for Usefulness of Mathematics and Effectance Motivation subscales, $p<.1$. No difference was found based on gender for the Father scale. 
Figure 1. Mean Mathematics as a Male Domain scores for all groups of subjects. Student Gender, $p<.05$ : Parent Gender, $p<.001$; Child's Gender (for Parents' scores), $p<.05$; Coaching Status, $p<.05$ (Dtrs $=$ daughters)

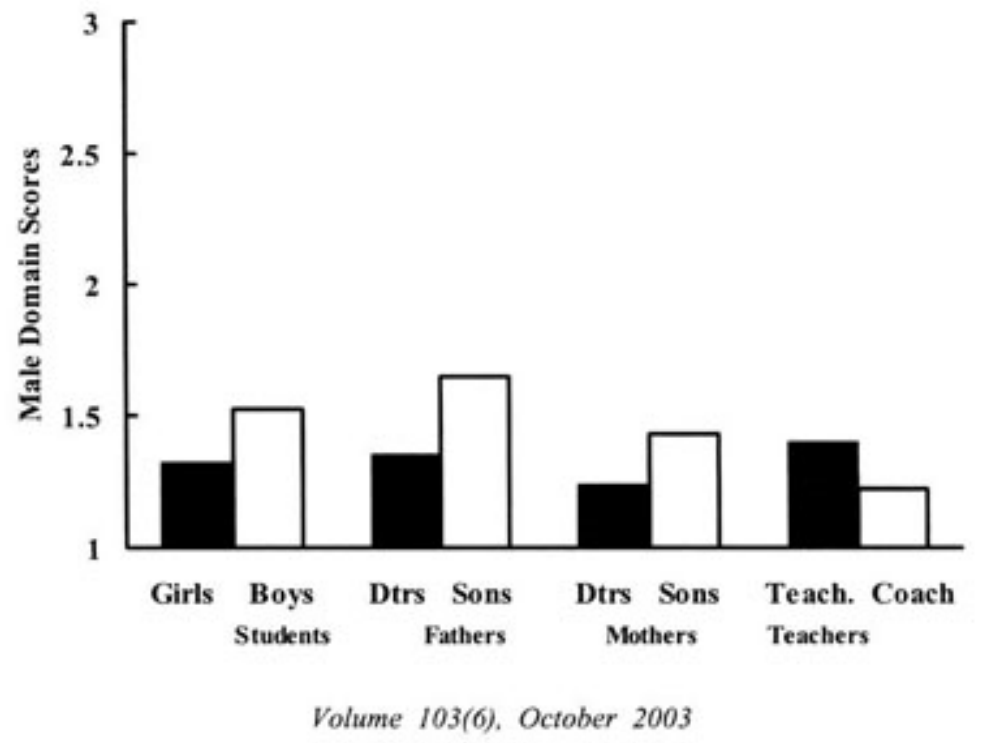

Sixty of the students responded to the question, "What does mathematics mean to you?" Twenty-two students gave generalized answers, such as, "Mathematics is important." The majority of these (19/22) were in either fourth or sixth grades. Another common theme, provided by 20 students, indicated an enjoyment of math. These statements included, "Mathematics is fun." Ten students indicated that mathematics is used in everyday life, 8 students connected mathematics with career aspirations, while 10 indicated that mathematics is important for their futures without referring to careers per se. No differences in these theme categories were found based on grade level or gender.

\section{Parents}

The parents' attitudes toward mathematics and their expectations for their children in mathematics were also analyzed. A total of 133 parents ( 80 mothers and 53 fathers) returned completed questionnaires. This represents a higher return rate for the mothers than for the students themselves (only 74 students responded), and a good return rate for fathers. There was an almost equal split between parents of girls and parents of boys $(48.9 \%$ and $51.1 \%$, respectively).

Two-way ANOVAs were used to compare the responses of the parents, using both the child's gender and the parent's gender as independent variables, for the two subscales of parents' attitudes towards mathematics. As shown in Figure 1, the fathers indicated a higher level of agreement than the mothers for the Mathematics as a Male Domain subscale, $F(1,129)=$ $11.86, p<.001$. There was also a significant difference for this subscale based on the gender of 
the child, with parents of boys showing more gender stereotyping of mathematics than parents of girls, $F(1,129)=8.62, p<.01$. There was no interaction between these two variables for this subscale.

No differences were found for the scores on the modified scale of parental expectations based on the parent's gender or the child's gender. However, there was a significant interaction between these two variables, $F(1,129)=4.09, p<.05$. The expectations of the mothers of girls and mothers of boys were essentially equal. However, the fathers of girls held higher expectations than the fathers of boys. No significant differences were found for the Mathematics Usefulness subscale.

An analysis of the parents' responses to the question, "What is the role of mathematics in our society today?" revealed several interesting findings. Following coding by two investigators, these replies were placed in the following categories: mathematics for calculations; mathematics in everyday life; mathematics for careers; and mathematics as a language or used for science. Overall, 39 parents, 30 mothers, and 9 fathers, stated that mathematics is used in daily life. This proportional difference between mothers and fathers was significant, [chi square] $(1)=6.48, p<$ .05. Of these statements referring to daily use of mathematics, 16 focused on using mathematics for calculations (e.g., shopping, paying bills, balancing checkbooks, cooking, or calculating interest). All of these responses were given by mothers.

None of the fathers' responses focused solely on using mathematics for calculations. Again, this represented a significant different in proportions between mothers and fathers, [chi square] (1) = 12.05, $p<.01$. In contrast, a higher proportion of fathers, compared to mothers, indicated that mathematics is used in science or as a language, with 12 fathers and only 8 mothers providing this type of answer, [chi square] (1) $=3.99, p<.05$. No gender difference was found for the proportion of parents stating that mathematics is used for careers.

\section{Teachers}

Questionnaires were distributed to the mathematics coaches of each of the 52 schools represented. A total of 35 coaches returned completed questionnaires. Additionally, 14 teachers of math, but not coaches, also returned completed questionnaires. These teachers were quite experienced, averaging 14.0 years of teaching, in general, and 12.7 years teaching math. There were no differences in experience level between the mathematics coaches and the noncoaches. Only six men completed the questionnaires, and all of these were coaches.

The scales developed for the teachers measured their motivation for Success in Mathematics, perception of Mathematics as a Male Domain, and perception of Usefulness of Math. One-way ANOVAs were used to compare scores on the three subscales, using coaching status as the main effect. Due to the small number of male teachers responding, gender was not tested. A significant difference was found for the Mathematics as a Male Domain scores, based on coaching status. As shown in Figure 1, those teachers who coach the mathematics teams showed less agreement with the Mathematics as a Male Domain than did the non-coaches, 
$F(1,47)=5.44, p<.05$. There were no differences between coaches and non-coaches for the Success in Mathematics subscale or Usefulness of Mathematics subscale.

Coaches were asked to indicate if they detected differences between male and female students in their preparation for the mathematics competition. The majority of the coaches denied such differences (70\%). Differences reported included that boys are more competitive and that girls are more serious and nervous. One coach indicated, "Girls are somewhat more reluctant, in general, but nothing like it was in the past." Another coach wrote, "Girls tend to be more interested in studying. The boys tend to rely more on what they know."

\section{Unsolicited Responses}

Several unsolicited responses were written on the survey form by girls, female teachers, and mothers. For instance, the mother of a daughter wrote, "I do not approve of the questions in this survey. They are very gender biased, something I thought this country was trying to discourage." Another wrote, "I thought we had progressed beyond these kinds of questions 20 years ago. I found them offensive and so did my daughter." An eighth-grade girl wrote, "sexist pig" next to seven of the Mathematics as a Male Domain questions, and referred to the researchers as "airheads." A female mathematics coach wrote, "Give me a break, pretty biased question, enough already! I'm getting insulted."

\section{DISCUSSION}

As we discuss the results of our research, we will focus on several difficult questions that must be answered if we are to make gains in mathematics education. First, we believe that there are still issues associated with gender bias. Next, we will consider responses that, while on the surface seem to support equal treatment of boys and girls, are not equitable for both genders. Finally, we will argue that beyond the issue of gender and the differences in learning styles, parents, teachers, and students must move away from the traditional association of mathematics with computational skills.

In the 1970s Fennema and Sherman's $(1976,1977)$ work indicated that gender differences exist in affective variables related to mathematics. Now, almost three decades later, we report that these differences still exist. In our study we found that, even in a sample of students chosen for their interest and aptitude in mathematics, the girls have less confidence in their abilities and view their mothers as having lower expectations for their success in math. Also, parental differences were noted, with the mothers more frequently focusing on the use of mathematics for computational tasks, while the fathers more frequently discussed mathematics as being connected to problem solving and symbol manipulation.

Perhaps more importantly, results of the analyses of the Mathematics as a Male Domain subscale indicate that boys, fathers, parents of sons, and non-coaching mathematics teachers more strongly support the belief that mathematics is a male domain, compared to girls, mothers, 
parents of daughters, and mathematics coaches. Looking at the individual statements within this subscale provides insight as to the basis of this stereotyped perception. For boys, girls, mothers, fathers, coaches, and teachers, the most strongly endorsed gender-biased statement was, "Men are naturally better at mathematics than women." In contrast, the most strongly endorsed non-biased statement was, "It is just as appropriate for women to study mathematics as for men." These statements exemplify the conflict: women and men should have equal opportunities for success in math, even though men have more natural talent than women.

This raises the question regarding to what extent the stereotyping of mathematics as a male domain is "merely" due to gender bias, or rather is due to real, inherent differences between girls and boys, men and women, in how they learn and think about mathematics. There is evidence from previous studies that children do indeed learn mathematics differently. For instance, as early as 1974, Maccoby and Jacklin reported that at around 12 years of age boys' mathematical skills increase faster than do girls'. Shibley-Hyde et al. (1990) found that gender differences, although small, occur in critical areas like problem solving. Further, Fennema et al. (1998), using a longitudinal design, found that in the early elementary grades girls are more likely to use standard algorithms, while boys invent new algorithms. The boys' approach assists them in solving more challenging problems that require flexibility.

However, this difference in learning rate and style may not be due to inherent differences in abilities, but rather may be a reflection of teaching methods and teachers' attitudes. For instance, teachers view girls as successful in mathematics due to their hard work (Jussim \& Eccles,1992; Siegle \& Reis, 1998), while they believe boys' success comes from their talent (Jussim \& Eccles, 1992). As expected based on these differences in attitudes, teachers also behave differently toward boys and girls in the classroom, responding preferentially to boys (AAUW, 1992; Becker, 1981).

\section{Areas of Change}

The literature studying the interactions of people's beliefs about human learning and education has been used to inform the ongoing mathematics education reform movement. Specifically, researchers have studied how belief structures about mathematics can affect preservice and inservice teacher practice, as well as performance and attitudes of the students (Raymond, 1997). These findings have been used to motivate changes in educational practice, with the desired goal of providing equitable educational experiences for all students, regardless of gender, learning style, or aptitude for mathematics. However, conflicts between belief systems and educational practices continue to act as a roadblock in this reform.

In 1992 the American Association of University Women released a study, Shortchanging America: A Call to Action, which documented the discouraging trend of girls becoming less confident in their mathematical abilities and less interested in pursuing advanced study in mathematics as they get older. In this study, teachers were warned about contributing to this trend by not recognizing and supporting achievements in mathematics and science. While we agree, we wish to extend this warning to cover each group that was investigated. Changing the 
attitudes of students, parents, and teachers is crucial for ongoing mathematics education reform.

First, the beliefs held by teachers regarding mathematics must undergo change. As Raymond (1997) reported, the teaching practice of beginning elementary school teachers is likely to be influenced by their deeply held beliefs about mathematics. These beliefs overshadow their teaching pedagogy and their practice strategies. Such beliefs are often more traditional in nature and result in the teachers concentrating on keeping a quiet atmosphere and the presentation of content, rather than on experimenting with teaching practices that were emphasized in their training.

An in-depth picture of the interactions within the mathematics classroom has recently been provided by an analysis of videotaped instruction in eighth-grade rooms in the United States and six other countries (Hiebert et al., 2003). The results of this study, conducted as part of the Third International Mathematics and Science Study, indicated that the United States mathematics classrooms are not geared towards conceptual and discovery learning. A "lesson signature," profiling how the classroom time is spent, indicated that in the United States, roughly the first half of each class is devoted to reviewing previously covered material. Following this review period, new material is presented, and students are then provided with time to solve a series of low to moderate complexity problems. Answers to these problems may be given, but little emphasis is placed on discussing the underlying concepts.

Such a lesson signature may result in a well-ordered classroom, likely to generate minimal frustration for both students and teachers. In contrast, acquiring higher-level knowledge may require a less structured approach. Learning difficult things can be a messy and emotional affair, and teachers and students alike have to become comfortable with this disarray. Teachers need to overcome their expectations of order.

Second, the students have to become comfortable with ambiguity. They need to be comfortable asking "why?" while still acquiring the basic skills. Uncertainty is anxiety producing, so we are asking a lot of our children. Teachers must help students, especially girls, manage the anxiety created by struggling with understanding the concepts. Rewarding the child's efforts in discovering the concepts must take precedence over rewarding the correct answer. This is especially true as more complex problems are presented for solving. This is a demanding requirement.

Finally, parents, as well as other adults, need to learn what mathematics really is. A deeper understanding about the nature of the discipline is essential to mathematics education. Parents must be able to respond, with confidence and depth, to the question, "Why is mathematics useful?" Parents, especially mothers, must move beyond the identification of mathematics solely with computational skills. 


\section{Conclusions}

This study is unique in that it combines results from three interrelated groups of respondents: mathematically talented students, their parents, and their mathematics teachers and coaches. By examining the three groups within one study design, we sought to elucidate the interactions amongst the primary social-environmental components. Our results point to the complexities of beliefs surrounding gender and mathematics abilities, and the influence of these beliefs on mathematics performance for boys and girls.

The data presented here extend findings of previous researchers regarding gender stereotyping (Duffy, Gunther, \& Walters, 1997; Fennema et al., 1998; Forgasz \& Leder, 1996; Junge \& Dretzke, 1995; Kloosterman, 1988; Meyer \& Koehler, 1990; Siegle \& Reis, 1998; Stipek \& Gralinski, 1991; Terwilliger \& Titus, 1995; Tocci \& Engelhard, 1991). The finding of decreased confidence in mathematics abilities in the present study shows that even girls who are particularly motivated and talented in mathematics are not immune to the ill effects of gender bias. Additionally, this study indicates a persistence of the belief that mathematics is a male domain. This is true not only for the students but also for the fathers, the parents of boys, and the non-coaching mathematics teachers. This is a clear indication that our efforts to rid our society of this stereotype have not been successful.

Importantly, the existence of this stereotype is not acknowledged by the girls and women. Instead, girls, female teachers, and mothers provided unsolicited comments on the survey form vehemently confronting the items in the male domain subscale. These comments centered on the idea that the survey was biased and insulting to women, and not accurate for current times. No such comments were written by boys, fathers, or male teachers. Obviously, if mathematics is still viewed as a male domain by men, and girls and women fail to acknowledge the existence of this bias, an unrealistic relationship is set up.

Indeed, these results point to the essence of the conflict: We have been schooled to discount the presence of real gender differences in mathematics. To discuss these differences, we seem to believe, is to perpetuate a gender bias. We argue here that the task is not to ignore or deny differences in learning styles, attitudes, and performance, but to acknowledge such differences as an essential first step in education reform. Designing strategies to provide equitable education, rather than equal opportunities, for both genders will require restructuring teachers' and parents' expectations of children's behaviors in the classroom. Although rewarding girls' propensity for observing rules and applying standard procedures may provide increased performance for the girls in the short term, it does not develop the flexibility in thinking that is needed for more complex problem solving. In the words of Sowder (1998), "It is ironic to think that a more traditional style of teaching, where emphasis is placed on rote learning of rules, may tend to better equalize the advantages of the girls and the boys. The trouble is, both sexes will then be disadvantaged" (p. 13).

We would extend our need for reform beyond the classroom. Parental practices regarding mathematics education are probably closely linked to their beliefs of what mathematics really is. The parents in our survey, especially the mothers, continue to hold the idea that mathematics can be equated with computational skills. 
In their 1948 book, the mathematicians Courant and Robbins asked the question, "What is Mathematics?" In 1997, Hersh asked the question, "What is mathematics, really?" We propose that the answer to this question, although not simple, is essential for effective mathematics education for both boys and girls. It may be in the realm of philosophers of mathematics and science to completely investigate this question, but teachers, students and parents must reconcile their knowledge of the discipline with current practice of mathematics education. 


\section{REFERENCES}

American Association of University Women. (1992). Shortchanging girls, shortchanging America: A call to action. Washington, DC: AAUW Initiative for Educational Equity.

Becker, J. R. (1981). Differential treatment of females and males in mathematics classes. Journal for Research in Mathematics Education, 12, 40-53.

Blevins-Knabe, B., \& Musun-Miller, L. (1991, April). Parental beliefs about the development of preschool children's number skills. Paper presented at the biennial meeting of the Society for Research on Child Development, Seattle, WA.

Courant, R., \& Robbins, H. (1948). What is mathematics? Oxford University Press: London.

Duffy, J., Gunther, G., \& Walters, L. (1997). Gender and mathematical problem solving. Sex Roles, 37, 477-494.

Fennema, E., Carpenter, T. P., Jacobs, V. R., Franke, M. L., \& Levi, L. W. (1998). A longitudinal study of gender differences in young children's mathematical thinking. Educational Researcher, 27, 6-11.

Fennema, E., \& Sherman, J. A. (1976). Fennema-Sherman Mathematics Attitude Scales: Instruments designed to measure attitudes toward the learning of mathematics by females and males. Catalog of selected documents in psychology, 6, 31 (MS. No. 1225).

Fennema, E., \& Sherman, J. A. (1977). Sex-related differences in mathematics achievement, spatial visualization and sociocultural factors. American Educational Research Journal, 14, 5171.

Forgasz, H. J., \& Leder, G. C. (1996). Mathematics classrooms, gender and affect. Mathematics Education Research Journal, 8, 129-137.

Hersh, R. (1997). Math lingo and plain English. Chemtech, 27(7), 64-65.

Hiebert, J., Gallimore, R., Garnier, H., Bogard-Givvin, K., Hollingsworth H., Jacobs, J., Chui, A. M.Y., Wearne, D., Smith, M., Kersting, N., Manaster, A., Tseng, E., Etterbeek, W., Manaster, C., Gonzales, P., \& Stigler, J. (2003). Teaching mathematics in seven countries: Results of the TIMSS 1999 video study [Online]. National Center for Education Statistics. Available: http://nces.ed.gov/pubsearch/ pubsinfo.asp?pubid=2003013

Junge, M. E., \& Dretzke, B. J. (1995). Mathematical self-efficacy gender differences in gifted/talented adolescents. Gifted Child Quarterly, 39, 22-28.

Jussim, L., \& Eccles, J. S. (1992). Teacher expectations II: Construction and reflection of student achievement. Journal of Personality and Social Psychology, 63(6), 947-961.

Kloosterman, P. (1988). Self-confidence and motivation in mathematics. Journal of Educational Psychology, 80, 345-351. 
Maccoby, E. E., \& Jacklin, C. N. (1974). The psychology of sex differences. Stanford, CA: Stanford University Press.

Meyer, M. R., \& Koehler, M. S. (1990). Internal influences on gender differences in mathematics. In E. Fennema \& G. Leder (Eds.), Gender and mathematics (pp. 60-95). New York: Teachers College Press.

Parsons, J. E., Adler, T. F., \& Kaczala, C. M. (1982). Socialization of achievement attitudes and beliefs: Parental influences. Child Development, 53, 310-321.

Raymond, A. M. (1997). Inconsistency between a beginning elementary school teacher's mathematics beliefs and teaching practice. Journal for Research in Mathematics Education, 28(5), 550-576.

Raymond, C. L., \& Benbow, C. P. (1986). Gender differences in mathematics: A function of parental support and student sex typing? Developmental Psychology, 22, 808-819.

Shibley-Hyde, J., Fennema, E., \& Lamon, S. J. (1990). Gender differences in mathematics performances: A meta-analysis. Psychological Bulletin, 107, 139-155.

Siegle, D., \& Reis, S. M. (1998). Gender differences in teacher and student perceptions of gifted students' ability and effort. Gifted Child Quarterly, 42, 39-47.

Sowder, J. T. (1998). Perspectives from mathematics education. Educational Researcher, 27, 611.

Stipek, D. J., \& Gralinski, J. H. (1991). Gender differences in children's achievement-related beliefs and emotional responses to success and failure in mathematics. Journal of Educational Psychology, 83(3), 361-371.

Terwilliger, J. S., \& Titus, J. C. (1995). Gender differences in attitudes and attitude changes among mathematically talented youth. Gifted Child Quarterly, 39, 29-35.

Tiedemann, J. (2000). Parents' gender stereotypes and teachers' beliefs as predictors of children's concept of their mathematical ability in elementary school. Journal of Educational Psychology, 92(1), 144-151.

Tocci, C. M., \& Engelhard, G. (1991). Achievement, parental support, and gender differences in attitudes toward mathematics. Journal of Educational Research, 84(5), 280-286.

von Glaserfeld, E. (1989). An exposition of constructivism: Why some like it radical Amherst, MA: University of Massachusetts monograph, Scientific Reasoning Research Institute. 